\title{
Perfil socioeconômico dos graduandos em Odontologia da Universidade Federal de Santa Catarina
}

Ana Cristina Latreille*; Silvio Machado Sobrinho**; Alessandra Martins Ferreira Warmling ${ }^{* * *}$; Dayane Machado Ribeiro ${ }^{* * * *}$, Cláudio José Amante ${ }^{* * * * *}$

* Graduanda em Odontologia. Universidade Federal de Santa Catarina, Florianópolis, SC

** Professor da Carreira do Magistério do Ensino Básico, Técnico e Tecnológico, Especialista, Mestrando do Programa de Pós-Graduação em Administração Universitária. Universidade Federal de Santa Catarina, Florianópolis, SC

*** Doutoranda em Odontologia, Universidade Federal de Santa Catarina, Florianópolis, SC

**** Professora do Departamento de Odontologia, DDS, PhD. Universidade Federal de Santa Catarina, Florianópolis, SC

**** Professor do Departamento de Odontologia, DDS, PhD. Universidade Federal de Santa Catarina, Florianópolis, SC

\section{RESUMO}

O objetivo deste estudo é estabelecer o perfil socioeconômico dos estudantes regularmente matriculados no Curso de Graduação em Odontologia da UFSC. Um questionário foi formulado e aplicado a 327 alunos, voluntários, regularmente matriculados no curso de graduação em Odontologia da Universidade Federal de Santa Catarina. O perfil socioeconômico do acadêmico da UFSC foi semelhante ao visto em outras universidades. Há predominância de alunos do sexo feminino, solteiros, sem filhos, da cor branca e com idade entre 21 e 25 anos. A grande maioria não participa de nenhum programa de assistência estudantil, é mantida pelos pais e acha o alto custo dos materiais um impedimento para a conclusão do curso. Recomenda-se que pesquisas sejam feitas para que o custo real dos materiais seja definido e, assim as políticas de assistência estudantil tenham um norte em que se basear para que possam ser eficientes.

Descritores: Fatores Socioeconômicos. Classe Social. Estudantes de Odontologia.

\section{INTRODUÇÃO}

Nos últimos anos, além da implantação das Diretrizes Curriculares Nacionais para os cursos de graduação na área da saúde $^{1}$ e de todos os programas voltados para a aproximação do ensino aos cenários de prática profissional (Pró-Saúde ${ }^{2}$ e o PET-Saúde ${ }^{3}$ ), o Governo Federal também instituiu outros programas, de fundamental importância para a expansão das Instituições Federais de Ensino Superior (IFES) e a permanência dos alunos no ensino superior até a sua diplomação, como os Programas de Ações Afirmativas, o Programa de Apoio ao Plano de Reestruturação e Expansão das Universidades Federais (REUNI) ${ }^{4}$ e o Plano Nacional de Assistência Estudantil (PNAES) ${ }^{5}$.

Os Programas de Ações Afirmativas visam combater a desigualdade em relação às oportunidades educacionais, com o propósito de potencializar o acesso de grupos minoritários à educação superior. São medidas especiais e temporárias adotadas pelo Estado, com o objetivo de eliminar desigualdades raciais, étnicas, religiosas, de gênero e outras, historicamente acumuladas, garantindo a 
igualdade de oportunidade e tratamento, bem como compensar perdas provocadas pela discriminação e marginalização ${ }^{6}$. Este seria um meio de diminuir as desigualdades e garantir o acesso de grupos menos favorecidos ao ensino superior, embora não resolva o problema de maneira definitiva, pois é preciso que as condições de permanência desses grupos sejam concretizadas ${ }^{7}$.

O REUNI (Decreto $n^{\circ}$ 6.096, de 24 de abril de 2007) ${ }^{4}$, tem como principal objetivo ampliar o acesso e a permanência na educação superior. Com ele, foi adotada uma série de medidas para retomar o crescimento do ensino superior público, criando condições para que as universidades federais promovam a expansão física, acadêmica e pedagógica da rede federal de educação superior. As ações do programa contemplam o aumento de vagas nos cursos de graduação, a ampliação da oferta de cursos noturnos, a promoção de inovações pedagógicas e o combate à evasão, entre outras metas que têm o propósito de diminuir as desigualdades sociais no país².

O PNAES (Decreto $\mathrm{n}^{0} 7.234$, de 19 de julho de 2010), objetiva fortalecer e democratizar as condições de permanência dos jovens na educação superior pública federal, minimizar os efeitos das desigualdades sociais e regionais na permanência e na conclusão da educação superior, reduzir as taxas de retenção e de evasão e contribuir para a promoção da inclusão social pela educação ${ }^{5}$.

Segundo o Fórum Nacional de PróReitores de Assuntos Comunitários e Estudantis (FONAPRACE), órgão assessor da Associação Nacional dos Dirigentes das Instituições Federais de Ensino Superior (ANDIFES), a busca da redução das desigualdades socioeconômicas faz parte do processo de democratização da universidade e da própria sociedade brasileira. Essa democratização não se pode efetivar, apenas, no acesso à educação superior gratuita. Torna-se necessá- ria a criação de mecanismos que garantam a permanência dos que nela ingressam, reduzindo os efeitos das desigualdades apresentadas por um conjunto de estudantes, provenientes de segmentos sociais cada vez mais pauperizados e que apresentam dificuldades concretas de prosseguirem sua vida acadêmica com sucesso. Em 1997, esse fórum, na tentativa de conhecer o perfil dos estudantes matriculados nas Instituições Federais de Ensino Superior (IFES), publicou uma pesquisa amostral do perfil socioeconômico e cultural dos estudantes de graduação das IFES a qual revelou que $44,29 \%$ dos alunos pertenciam às classes $\mathrm{C}, \mathrm{D}$ e $\mathrm{E}^{8}$.

Em 2010 o FONAPRACE atualizou as suas informações e identificou novos parâmetros para embasar a implantação da política de assistência estudantil, principalmente em relação à expansão dos benefícios destinados a garantir as condições de permanência e conclusão de curso dos estudantes em (situação de) vulnerabilidade socioeconômica. Nesse novo estudo, foi verificado que $44 \%$ dos estudantes pertenciam às classes $\mathrm{C}, \mathrm{D}$ e $\mathrm{E}$, praticamente o mesmo resultado obtido na ultima pesquisa ${ }^{9}$.

No mesmo sentido, a Constituição da República Federativa do Brasil, (de 1988), no seu Art. 205 determina que a educação é direito de todos e dever do Estado e da família e, no seu artigo Art. 206, disciplina a igualdade de condições para o acesso e permanência na escola, bem como a gratuidade do ensino público em estabelecimentos oficiais ${ }^{10}$.

Aliado a estes dados apresentados pela ANDIFES e pelo FONAPRACE, essas Políticas Públicas também favoreceram o acesso de estudantes com vulnerabilidade socioeconômica nos Cursos de Graduação em Odontologia (das Universidades Públicas Federais). Porém, sabe-se que a permanência destes alunos pode vir a ficar comprometida, em virtude do elevado custo para aquisição • 15(1): 86-96, 2015. 
de materiais e instrumentais necessários para as práticas clínicas e laboratoriais.

Frente a este contexto, esta pesquisa objetiva estabelecer o perfil socioeconômico dos estudantes regularmente matriculados no Curso de Graduação em Odontologia da Universidade Federal de Santa Catarina (UFSC).

\section{MÉTODO}

Trata-se de uma pesquisa descritiva, a qual traça, por meio de um questionário estruturado, o perfil socioeconômico dos estudantes do curso de graduação em Odontologia da UFSC. De natureza aplicada, pois operacionalizou de forma sistemática os conceitos que estabeleceram o tal perfil socioeconômico, além de utilizá-los para solucionar possíveis problemas revelados pelos resultados obtidos.

A obtenção dos dados foi realizada por intermédio de um questionário estruturado individual, já validado na literatura. Foi utilizado o mesmo questionário do FONAPRACE $(2010)^{8}$, que teve por objetivo de traçar o perfil econômico e cultural do estudante de graduação presencial das universidades federais brasileiras com o intuito de obter subsídios para a ANDIFES poder definir com mais rigor metodológico o futuro da educação federal, no âmbito superior, do Brasil $^{8}$.

O universo dos sujeitos da pesquisa foram os 508 alunos regularmente matriculados na Coordenadoria do Curso de Graduação em Odontologia da UFSC.

O projeto referente a esta pesquisa foi submetido ao Comitê de Ética e Pesquisa com Seres Humanos da UFSC, tendo sido aprovado (parecer $\left.n^{0}: 388.009 / 13\right)$. Todos os participantes foram convidados a participar voluntariamente do estudo e assinaram o Termo de Consentimento Livre e Esclarecido.

A coleta de dados foi realizada pela pesquisadora, no mês de setembro de 2013, durante as aulas teóricas.

Para a análise dos dados foi utilizado o software EpiData para a estruturação de um banco de dados. A partir dessas informações organizadas foram feitas associações entre as variáveis utilizando o software EpiData Analysis, para em seguida gerar as tabelas e gráficos utilizando o Microsoft Excel.

\section{RESULTADOS}

Participaram deste estudo 327 alunos, regularmente matriculados no curso de graduação em Odontologia da Universidade Federal de Santa Catarina. Em relação ao sexo dos alunos participantes, 228 eram do sexo feminino e 99 do masculino. Quanto à idade, a grande maioria dos estudantes (299) era na faixa entre 18 a 24 anos.

Ao analisar a distribuição absoluta e relativa da faixa etária e do sexo dos alunos foi verificado que, tanto para o sexo masculino, quanto para o sexo feminino, a grande maioria era entre 18 a 24 anos. Poucos alunos apresentaram idade menor de 18 anos e, apesar de ser um resultado um pouco maior, porém também de pequena dimensão, poucos exibiram idade maior que 24 anos para ambos os sexos (Tabela 1). 
Tabela 1 - Dispersão absoluta (N) e relativa (\%) da faixa etária e do sexo dos estudantes participantes do estudo

\begin{tabular}{|c|c|c|c|c|c|c|}
\hline \multirow[t]{3}{*}{ FAIXA ETÁRIA } & \multicolumn{6}{|c|}{ SEXO } \\
\hline & \multicolumn{2}{|c|}{ Feminino } & \multicolumn{2}{|c|}{ Masculino } & \multicolumn{2}{|c|}{ TOTAL } \\
\hline & $\mathrm{N}$ & $\%$ & $\mathrm{~N}$ & $\%$ & $\mathrm{~N}$ & $\%$ \\
\hline Até 17 anos & 04 & 1,22 & 01 & 0,30 & 05 & 1,52 \\
\hline De 18 a 24 anos & 212 & 64,83 & 87 & 26,60 & 299 & 91,43 \\
\hline 25 anos ou mais & 12 & 3,66 & 11 & 3,36 & 23 & 7,03 \\
\hline TOTAL & 228 & 69,72 & 99 & 30,27 & 327 & 100 \\
\hline
\end{tabular}

Em referência a raça/cor/etnia a grande maioria dos estudantes se autodeclararam de cor branca (292 alunos). Em referência as outras qualificações públicas de si mesmo, o segundo resultado mais encontrado foi para a cor parda, o menor para a amarela e apenas 01 aluna se autodenominou como outra cor/raça/etnia.
Na Tabela 2 encontra-se a distribuição absoluta (N) e relativa (\%) da população por sexo e cor dos alunos. É impressionante a presença marcante de alunos que se autodeclaram brancos e pouco resultado numérico de pessoas que se autodenominam como parda, preta, amarela e outra sem definição, em ambos os sexos.

Tabela 2 - Dispersão absoluta (N) e relativa (\%) do sexo e da raça/cor/etnia

\begin{tabular}{|c|c|c|c|c|c|c|c|c|c|c|c|c|}
\hline \multirow[t]{3}{*}{ SEXO } & \multicolumn{10}{|c|}{ RAÇA/COR/ETNIA } & \multicolumn{2}{|c|}{ TOTAL } \\
\hline & \multicolumn{2}{|c|}{ Amarela } & \multicolumn{2}{|c|}{ Branca } & \multicolumn{2}{|c|}{ Parda } & \multicolumn{2}{|c|}{ Preta } & \multicolumn{2}{|c|}{ Outra } & \multirow[b]{2}{*}{$\mathrm{N}$} & \multirow[b]{2}{*}{$\%$} \\
\hline & $\mathrm{N}$ & $\%$ & $\mathrm{~N}$ & $\%$ & $\mathrm{~N}$ & $\%$ & $\mathrm{~N}$ & $\%$ & $\mathrm{~N}$ & $\%$ & & \\
\hline Feminino & 1 & 0,3 & 202 & 61,77 & 17 & 5,19 & 7 & 2,14 & 1 & 0,3 & 228 & 69,75 \\
\hline Masculino & 4 & 1,22 & 90 & 27,52 & 4 & 1,22 & 1 & 0,3 & 0 & 0 & 99 & 30,3 \\
\hline TOTAL & 5 & 1,52 & 292 & 89,29 & 21 & 6,42 & 8 & 2,44 & 1 & 0,30 & 327 & 100 \\
\hline
\end{tabular}

A situação conjugal dos alunos revelada aponta para a grande maioria ser solteiro. Habitando com outra pessoa, de forma estável (casado ou vivendo com o companheiro) foi o segundo maior resultado. Apesar da grande maioria dos alunos apresenta- rem uma idade inferior a 24 anos, também foi revelado que uma estudante já se apresenta na condição de viúva (Gráfico 1). A grande maioria dos estudantes (320) não possuem filhos. 
Gráfico 1 - Dispersão da situação conjugal dos alunos

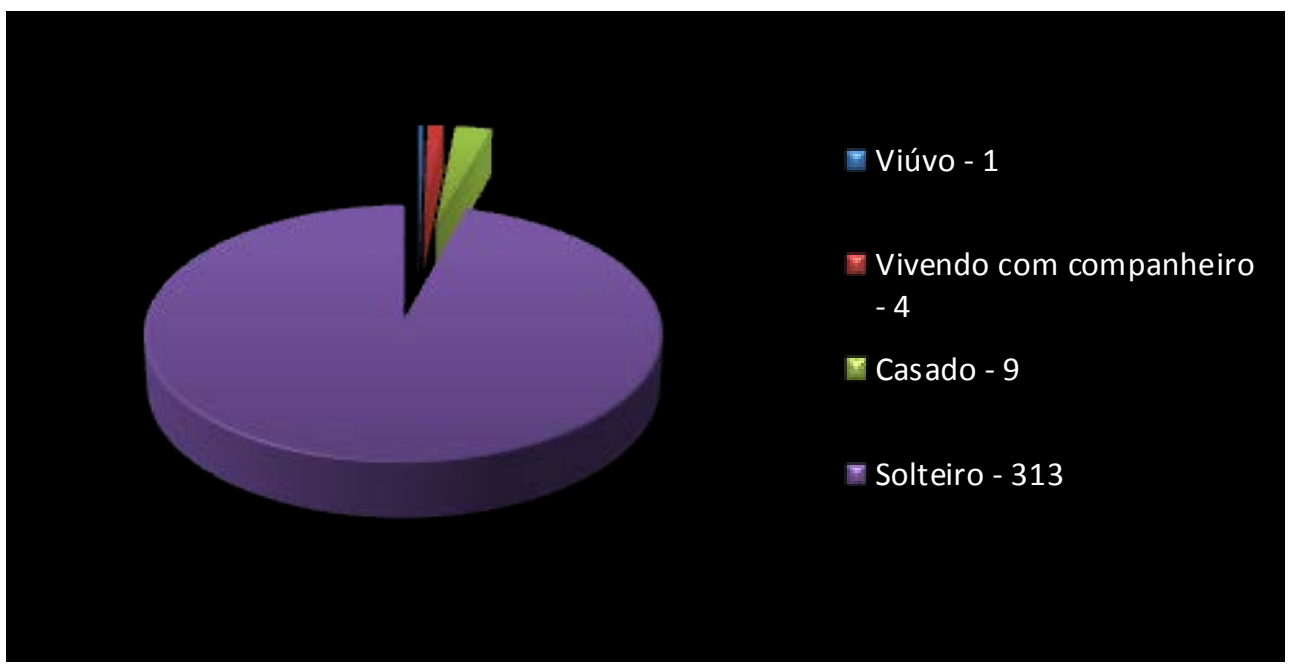

No que concerne à renda bruta mensal integram a C1 e somente 3 alunos se enquafamiliar do estudante, observou-se que a dram na classe C2, com renda média de R\$ maioria pertence a classe A (133 alunos), 1.147,00. Nenhum aluno foi classificado nas com renda média de R\$ 9.263,00, outros 22 classes D e E (Gráfico 2).

alunos têm renda média de $\mathrm{R} \$ 1.685,00$ e

Gráfico 2 - Dispersão dos alunos de acordo com sua renda média

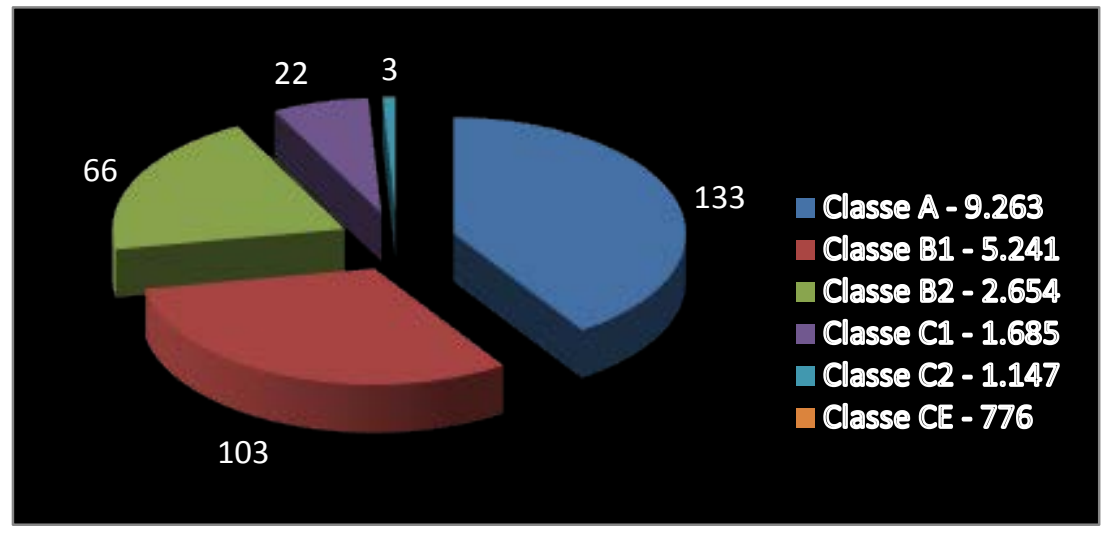

A maior quantidade de alunos ficou situada na classe A, tanto para o sexo feminino, quanto para o sexo masculino. Contudo, observa-se que, em referência a classe $B$, que está subdivida em dois segmentos, se fosse realizada a somatória desta subdivisão, o resultado seria outro e a classe $B$ possuiria a maior parte dos estudantes, seguido pelas classes A e C1 e C2. Em relação ao sexo masculino, a classe A reuniu um número um pouco maior, 48 (14,67\%) alunos, em relação com a somatória da classe B, 45 (13,75\%) alunos. O sexo feminino apresentou um resultado inverso e mais expressivo, 124 (37,91\%) alunas pertencem à somatória da classe B e 85 (25,99\%) de alunas na classe A.

Quando perguntados sobre sua situação de moradia a maioria dos alunos afirmou morar com os pais (143 alunos). Mas, se as categorias, (a) sozinho, (b) casa de familiares, (c) casa de amigos, (d) república e (e) moradia mantida pela família fossem agrupadas em uma única categoria, a situação se inverteria e percebe-se então que 166 alunos 
não residem com os pais. Nota-se que apenas 3 alunos residem na moradia estudantil e 10 alunos moram com seus cônjuges (Gráfico 3).

Gráfico 3 - Dispersão dos alunos de acordo com sua situação de moradia

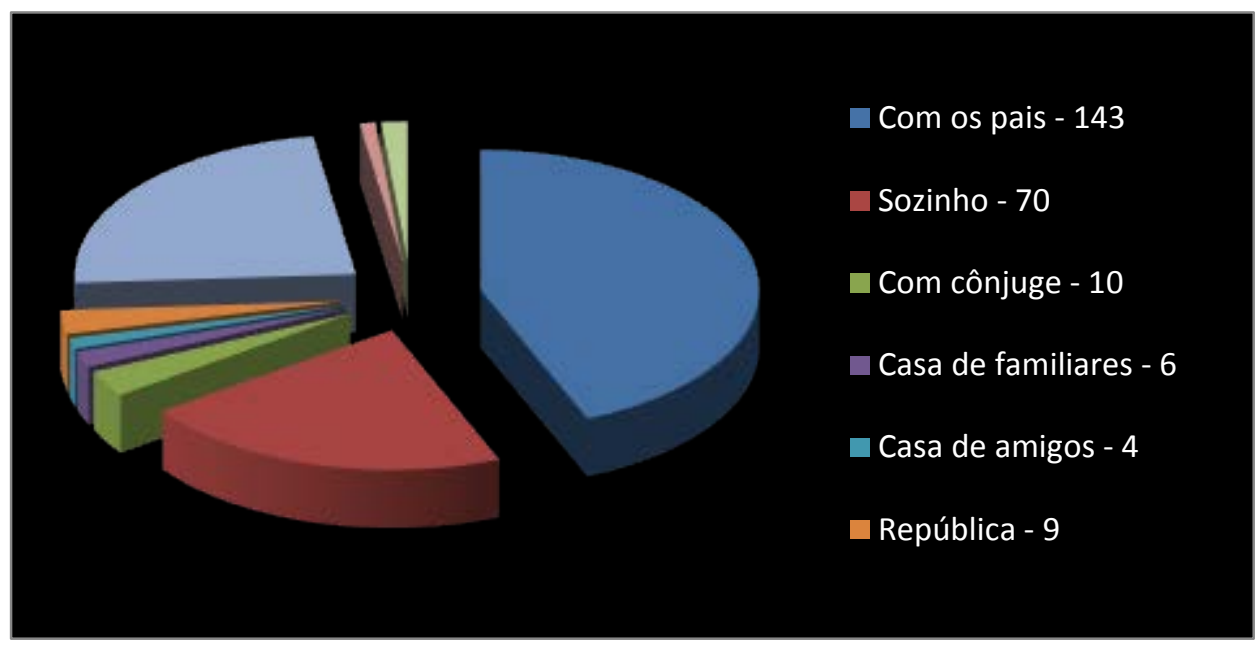

Percebeu-se que os 03 alunos que afirmaram residir na moradia estudantil são do sexo feminino. Em torno de 30\% das alunas residem na casa dos pais. Dos representantes do sexo masculino apenas 02 vivem com cônjuge, já dos entrevistados do sexo feminino 8 afirmaram morar com seus cônjuges.

Notou-se que apenas 01 aluno da classe A mora em republica. E, além disso, a maioria dos alunos da classe $\mathrm{B}$ reside com os pais.
Foi percebido que a grande maioria dos alunos acha que o alto custo dos materiais é um impedimento para a conclusão do curso. Além disso, percebeu-se que uma pequena parcela dos alunos participa de algum programa de assistência estudantil, sendo 288 alunos que não ganham nenhum auxilio da universidade (Gráfico 4). E que dos 25 alunos da classe $C$, apenas 12 participam de algum tipo de assistência estudantil fornecido pela Universidade.

Gráfico 4 - Dispersão dos alunos referente ao alto custo dos materiais e a participação em algum tipo de assistência estudantil dos estudantes

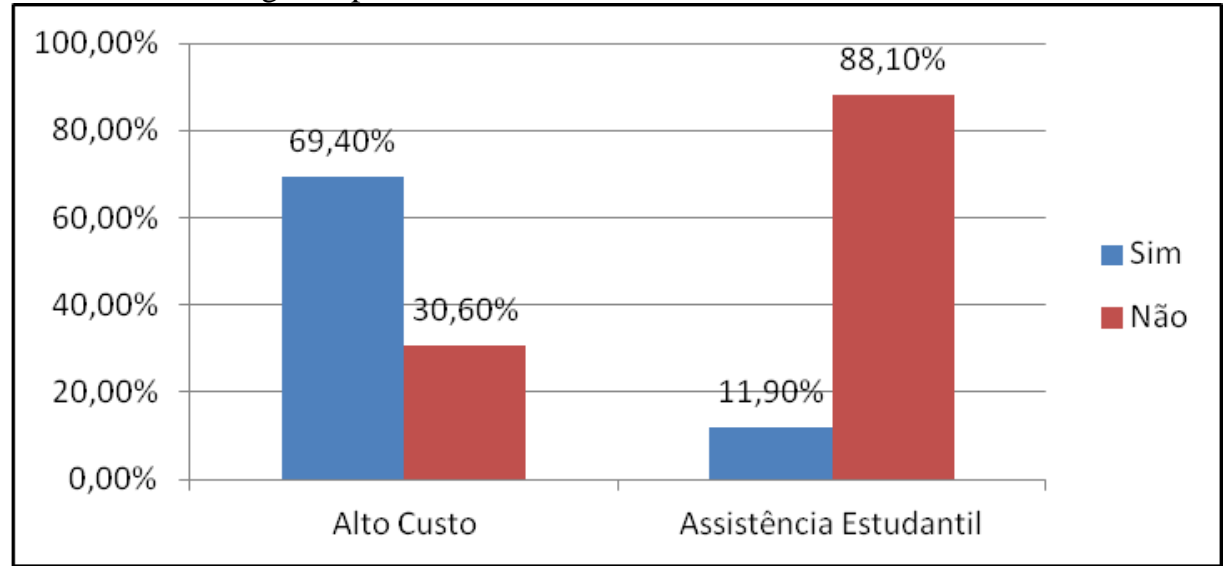




\section{DISCUSSÃO}

Observou-se, neste estudo, a ocorrência da feminização na Odontologia e este resultado está em concordância com vários estudos $^{7,11-15}$. Essa tendência ao aumento do número de mulheres nos cursos de Odontologia pelo país pode ser fruto da mudança da economia brasileira nas últimas décadas. $\mathrm{O}$ aumento do grau de escolaridade e a facilidade de acesso ao ensino superior oportunizaram às mulheres o acesso a trabalhos preferencialmente masculinos ${ }^{14}$.

De acordo com Rezende et al. $(2007)^{12}$, essa feminização na Odontologia pode se justificar pelo fato das mulheres, geralmente, serem mais delicadas e possuírem mais habilidades manuais que os homens, características indispensáveis no exercício da Odontologia.

Pode-se observar que essa tendência é comprovada, também em outros cursos, por um estudo feito pelo FONAPRACE (2010), com os estudantes da graduação das Universidades Federais, onde 53,5\% são do sexo feminino ${ }^{8}$.

Segundo, Moimaz, Saliba e Bueno $(2003)^{16}$ antigamente a força de trabalho feminina não era necessária no orçamento familiar, porém essa situação vem sendo modificada juntamente com a cultura e a oferta de melhores salários. Além disso, esses autores afirmam que a odontologia vem sendo um curso de escolha entre as mulheres por proporcionar certa autonomia na carga horária de trabalho, possibilitando assim que elas conciliem a sua jornada profissional com a de mãe.

Outro dado relevante na população estudada é o fato de $65,4 \%$ terem idade entre 21 e 25 anos. Semelhante ao que afirmam Junqueira et al (2002) ${ }^{17}$ em estudo feito com alunos do $1^{\circ}$ e $4^{\circ}$ anos do curso integral diurno e $1^{\circ}$ e $2^{\circ}$ anos do curso noturno da Faculdade de Odontologia de São José dos Cam- pos - UNESP, em abril de 2000, foi constatado que a maior parte dos alunos possuía idade entre 17 e 23 anos.

Isso também acontece na Universidade Estadual de Londrina, onde 86,87\% têm idade de até 26 anos $^{18}$. Esse resultado também está de acordo com vários outros estudos ${ }^{7,11-15,19}$. Segundo Pieper e Bueno (2010) ${ }^{13}$ essa baixa faixa etária pode indicar uma boa condição socioeconômica dos pais, pois os alunos puderam se dedicar aos estudos durante o ensino médio e se preparar para passar no vestibular de Odontologia, provavelmente, sem precisar dividir seu tempo entre trabalho e estudos.

Segundo a Resolução Normativa $\mathrm{N}^{\mathrm{o}}$ 008/CUN/2007, de 10 de julho de 2007, as ações afirmativas entraram em vigor no início de 2008 na Universidade Federal de Santa Catarina, reservando $10 \%$ das suas vagas para candidatos autodeclarados negros e que cursaram integralmente o ensino fundamental e médio em instituições públicas. Apesar disso, somente $2,4 \%$ dos alunos de graduação em Odontologia dessa universidade se autodeclaram negros, o que indica que o curso ainda é pouco heterogêneo ${ }^{2}$.

Diferente do que foi detectado na UFMA, onde se observou que depois que foi instituído o sistema de cotas o número de alunos auto declarados negros subiu de 3 para 22 alunos, indicando que o sistema de cotas já estava sendo efetivo nessa universidade $^{14}$.

A imensa maioria (95,7\%) dos alunos de graduação em odontologia da UFSC são solteiros e 97,9\% não têm filhos, semelhante a outros estudos ${ }^{11-13,18}$ como ocorre na Universidade Federal do Maranhão, onde 94,6\% dos alunos eram solteiros e $97,5 \%$ não tinham filhos ${ }^{14}$. Esse dado reflete o que acontece na sociedade brasileira atual onde as pessoas têm optado por casar-se mais tarde, priorizando a sua carreira e ascensão profisRevista da ABENO • 15(1): 86-96, 2015. 
sional $^{20}$.

No que se referiu à situação habitacional dos acadêmicos, mais de $50 \%$ da população deste presente estudo, não moram na casa dos pais, em algum tipo de moradia mantida pelos pais ou familiares. Isto poderia estar relacionado com o fato do único curso de Odontologia da rede pública do estado de Santa Catarina ser da UFSC, localizado em Florianópolis. Por isso, talvez, estudantes vêm para a capital para poder cursar a faculdade, necessitando sair da casa dos pais durante esse período. Esta ideia deveria ser averiguada com mais precisão em outros projetos de investigação.

Situação diferente à encontrada na pesquisa feita pelo FONAPRACE (2011) com os estudantes da graduação das Universidades Federais onde cerca de $30 \%$ dos alunos não residiam com os pais ${ }^{8}$. E no estudo feito na UFMA por Silva et al (2011), esse dado também se inverte lá $72 \%$ dos alunos vivem com os pais ${ }^{14}$.

Provavelmente, o fato do curso de odontologia da UFSC ser diurno, impossibilita que os alunos tenham uma atividade profissional remunerada, por isso 94\% da amostra não trabalha, o que os obriga a ser sustentado pelos pais ou outros familiares para que possam concluir o curso. Mais de 73\% declaram que o pai é o principal mantenedor da família. Este resultado revelado acima, está em concordância com outros estudos ${ }^{11,13,14}$.

Já em relação ao trabalho durante a formação acadêmica, Pieper e Bueno (2010), acreditam que a ocorrência de poucos alunos trabalharem está associada a alta carga horária exigida no curso de Odontologia, e ao fato das aulas serem diurnas ${ }^{13}$.

Essa situação muda um pouco quando se compara a Odontologia com outros cursos da Universidade Estadual de Londrina. Nesta instituição, do total de alunos matriculados em todos os cursos, 25,9\% trabalham em tempo integral ${ }^{18}$.

O FONAPRACE foi criado para fortalecer as políticas de assistência estudantil e tem por objetivo garantir a permanência dos alunos na graduação e assegurar que esses tenham condições de ter um bom desempenho durante o curso. Levando em consideração essas premissas e que o ensino púbico deveria ser totalmente gratuito entramos em contradição no que diz respeito aos materiais e instrumentais utilizados para formação, pois os alunos de graduação em Odontologia precisam comprá-los para a conclusão do curso.

Entretanto, foi constatado que apenas $11,9 \%$ dos alunos da graduação em Odontologia da UFSC, participam de algum tipo de assistência estudantil, porém do total da amostra apenas 3,7\% recebem esse material integralmente da universidade. Este fato revela que, a grande maioria dos estudantes necessita de algum tipo de do auxilio financeiro (dos pais, de parentes, etc) ou mesmo surge à necessidade de encontrar algum um trabalho, compatível com sua intensa carga de estudo, para realizar a compra desse material. E em casos mais graves ocorre até o trancamento da matrícula ou a desistência do curso.

Essa baixa adesão aos programas de assistência estudantil também está presente em outros estudos ${ }^{11,13,14}$. Silva et al. (2011) afirmam que na UFMA o fato de poucos alunos participarem de atividades acadêmicas remuneradas se deve ao fato de essas só serem oferecidas depois do quarto período e mesmo assim o número de bolsas é muito pequeno, deixando muitos alunos sem a possibilidade de ganhá-las ${ }^{14}$.

É importante ressaltar que as universidades deveriam fazer um acompanhamento do desempenho desses alunos que recebem auxílio da universidade. Pois, verificou-se que as universidades que fizeram esse acomRevista da ABENO • 15(1): 86-96, 2015. 
panhamento registraram que o desempenho desses alunos é estatisticamente igual aos dos alunos de condição socioeconômica melhor.

Em relação à condição econômica dos graduandos a maior parte da amostra está situada nas classes B1 e B2, tendo uma renda mensal na faixa de $\mathrm{R} \$ 5.241,00$ a $\mathrm{R} \$$ 2.654,00. Segundo Junqueira et al (2002) a maior população dos alunos da Faculdade de Odontologia de Araraquara se encontra na faixa de renda de $\mathrm{R} \$ 2.401,00$ a $\mathrm{R} \$$ $6.000,00^{17}$. Pieper e Bueno (2010) também comprovam esse dado, pois, dos alunos de Odontologia da UFPEL 36,11\% tinham renda familiar entre cinco e dez salários mínimos $^{13}$.

No curso da Odontologia no Centro Universitário de João Pessoa, 34,4\% dos alunos apresentam faixa de renda de 6 a 10 salários mínimos ${ }^{15}$. Ainda em concordância com essa informação Oliveira et al. (2013) constataram que na UESB, 50\% dos alunos de odontologia tinham renda familiar na faixa de R\$ 2.041,00 a R\$ 6.000,007.

Apesar do curso de odontologia ainda ser considerado um curso elitizado, de pessoas com bom poder aquisitivo, grande parte $(69,4 \%)$ da população estudada acha que o alto custo dos materiais odontológicos é um impedimento para a conclusão do curso.

Segundo consulta informal com as empresas que vendem os materiais e os instrumentais para os alunos da UFSC, estimase que seja gasto em torno de 15 mil reais com a compra dos materiais necessários para a execução das atividades práticas durante o curso de Odontologia. Levando em consideração que a duração do curso é de 60 meses, é gasto em torno de 250 reais por mês com materiais. Para uma família classe B2, que possui uma renda mensal de cerca de 2.600 reais, fica difícil disponibilizar $10 \%$ da renda familiar todo mês para arcar com as despesas dos materiais.
Em relação à compra de materiais e instrumentais necessários para a formação acadêmica, que é feita pelos alunos, é importante salientar que ela está em discordância com os preceitos da Constituição Brasileira que determina que o Ensino Público seja gratuito. Entretanto, segundo Pieper e Bueno (2010), embora a grande maioria dos alunos em graduação em Odontologia tenha renda familiar superior a cinco salários mínimos, não pode ser considerada uma renda alta, pois o curso de odontologia despende de muitos custos com materiais a sua realização ${ }^{13}$.

\section{CONCLUSÕES}

Através desta pesquisa concluiu-se que os alunos de graduação em odontologia da Universidade Federal de Santa Catarina são na sua maioria mulheres, solteiras, com idade entre 18 e 24 anos, brancas, sem filhos e não residem com os pais. Além disso, a maior parcela dos alunos é da classe $\mathrm{B}$, mas mesmo assim a maioria acha que o alto custo dos materiais é um impedimento para a conclusão do curso.

Ressalta-se que mais da metade dos alunos não residem com os pais, o que gera gastos com moradia, alimentação e transporte, considerando que o curso é em tempo integral, impossibilitando o aluno de trabalhar. Todos esses fatores encarecem muito a permanência desse acadêmico no curso e até dificultam sua conclusão, o que torna indispensável uma maior atenção da universidade para essa questão. É necessário tornar o ensino totalmente gratuito e disponibilizar o material solicitado pelas disciplinas para que seja garantida a permanência desses alunos na graduação.

A contribuição deste estudo reside no fato dele revelar temas e propostas de pesquisas direcionadas para ampliar o conhecimento sobre o perfil do estudante, as suas necesRevista da ABENO • 15(1): 86-96, 2015. 
sidades e a sua realidade. Ele deixa informações que podem ser utilizadas em estudos posteriores e/ou na melhoria da assistência estudantil para os alunos da Odontologia da UFSC.

Recomenda-se, ainda, a realização de pesquisas complementares para que o custo real dos materiais seja definido e, assim, as políticas de assistência estudantil tenham um norte em que se basear para que possam ser eficientes.

\section{REFERÊNCIAS}

1. Brasil. Conselho Nacional de Educação. Câmara de Educação Superior. Resolução CNE/CES 3/2002 de 4 de março de 2002. Dispõe sobre as diretrizes curriculares nacionais do curso de graduação em odontologia. Disponível em: http://portal.mec.gov.br/cne/arquivos/pdf /CES032002.pdf

2. BRASIL. Ministério da Saúde. Ministério da Educação. Programa Nacional de Reorientação da Formação Profissional em Saúde - Pró-Saúde: objetivos, implementação e desenvolvimento potencial. Brasília: Ministério da Saúde, 2007.

3. BRASIL. Ministério da Saúde. Portaria Interministerial $n^{0} 1.802$, de 26 de agosto de 2008. Institui o Programa de Educação pelo Trabalho para a Saúde - PETSaúde. Diário Oficial da União, Brasília, 26 ago. 2008. Seção 1, p.27.

4. BRASIL. Decreto $\mathrm{N}^{0}$ 6.096, de 24 de abril de 2007. Institui o Programa de Apoio a Planos de Reestruturação e Expansão das Universidades Federais REUNI, Poder Executivo, Brasília, DF, 24 abr. 2007.

5. BRASIL. Decreto $\mathrm{N}^{\circ} 7.234$, de 19 de julho de 2010. Dispõe sobre o Programa Nacional de Assistência Estudantil PNAES. Poder Executivo, Brasília, DF, 19 jul. 2010.
6. Seiffert OMLB, Hage SM. Políticas de Ações Afirmativas para a Educação Superior no Brasil: da intenção à realidade. In: Bittar M., Oliveira JF, Morosini M. (Orgs). Educação Superior no Brasil: 10 anos pós-LDB. Brasília: Instituto Nacional de Estudos e Pesquisas Educacionais Anísio Teixeira; 2008. p. 137-62.

7. Oliveira DL, Souza ES, Batista FJN, Alves JV. Yard SD. Perfil do aluno de Odontologia da Universidade Estadual do Sudoeste da Bahia - UESB. Rev. Saúde. Com 2013; 9(3):2-11.

8. Fórum Nacional de Pró-Reitores de Assuntos Comunitários e Estudantis. Assistência Estudantil uma questão de investimento. 2001. Disponível em: www.unb.br/administracao/decanatos/da c/fonaprace/documentos/assist_est.html.

9. Associação Nacional dos Dirigentes das Instituições Federais de Ensino Superior. Perfil Socioeconômico e Cultural dos Estudantes de Graduação das Universidades Federais Brasileiras. Brasília: Fórum Nacional de Pró-Reitores de Assuntos Comunitários e Estudantis (FONAPRACE) - DF, 2011.

10. Brasil. Constituição (1988). Constituição da República Federativa do Brasil. Brasília, DF: Senado Federal; 1988.

11. Brustolin J, Brustolin J, Toassi RFC, Kuhnen M. Perfil do acadêmico de Odontologia da Universidade do Planalto Catarinense - Lages - SC. Rev. ABENO 2006; 6(1):70-6.

12. Rezende FP, Nakanishi FC, Machado ACP, Quirino MRS, Anbinder AL. Perfil, motivações e expectativas dos graduandos e graduados em odontologia. Rev UNICID, São Paulo 2007; 19(2):165-72.

13. Pieper CM, Bueno M. Perfil Socioeconômico dos estudantes de Odontologia da Universidade Federal de Pelotas-RS. XII ENPOS II Mostra Científica. 2010 
Nov 9-11; Pelotas: 2010. Disponível em: http://www.ufpel.edu.br/cic/2010/cd/pdf/ CS/CS_01409.pdf.

14. Silva AC, Franco EL, Assunção HRM, Costa JF. Perfil do acadêmico de odontologia de uma universidade pública. Revista Pesq. Saúde 2011; 12(1):22-6.

15. Leite DFBM, Trigueiro M, Martins IMCLB, Lima Neto, TJ Santos MQ. Perfil socioeconômico de 253 graduandos de Odontologia de uma instituição privada em João Pessoa-PB em 2011. J Health Sci Inst. 2012; 30(2):117-9.

16. Moimaz, SAS, Saliba NA, Blanco MRB. A força do trabalho feminino na Odontologia, em Araçatuba - SP. J Appl Oral Sci 2003; 11(4): 301-5.

17. Junqueira J.C., Colombo CED, Tavares PG, Rocha RF, Carvalho YR, Rodrigues JR. Quem é e o que pensa o graduando de Odontologia. Rev.Odontol. UNESP 2002; 31(2):269-84.

18. Finatti, BE, Alves JM, Silveira RJ. Perfil Sócio, Econômico e Cultural dos Estudantes da Universidade Estadual de Londrina - UEL - Indicadores para implantação de uma política de assistência estudantil. Libertas 2007; 2(1):188-206.

19. Costa SM, Durães SJA, Abreu MHNG. Feminilização do curso de odontologia da Universidade Estadual de Montes Claros. Ciênc. Saúde Col. 2010; 15(Supl. 1):1865-1873.

20. Spíndola T, Martins ERC, Francisco MTR. Enfermagem como opção: perfil de graduandos de duas instituições de ensino. Rev. Bras. Enferm. 2009; 61(2): 164-9.

\section{ABSTRACT \\ Socioeconomic profile of graduates in Den- tistry, Federal University of Santa Catari- na}

The aim of this study was to establish the socioeconomic profile of students enrolled in the Graduate Course in Dentistry, UFSC. A questionnaire was formulated and applied to 327 students, volunteers, enrolled in undergraduate degree in Dentistry, Federal University of Santa Catarina. The socioeconomic profile of the academic UFSC was similar to that seen in other universities. There is a predominance of female students, unmarried, childless, of white and aged between 21 and 25 years. The vast majority does not participate in any assistance program student, is maintained by parents and think the high cost of materials an impediment to the completion of the course. It is recommended that research be done to the actual cost of materials is defined and thus policies have a North student assistance to be based in order to be efficient.

Descriptors: Socioeconomic Factors. Social Class. Dental Students.

Correspondência para:

Cláudio José Amante

e-mail claudiojosea@yahoo.com.br

Universidade Federal de Santa Catarina

Centro Ciências da Saúde, Departamento de odontologia - Campus Universitário Reitor João David Ferreira Lima

Trindade 88040-970 - Florianópolis/SC 